\title{
Biological indicators for pollution detection in terrestrial and aquatic ecosystems
}

\author{
Alaa Zaghloul ${ }^{1 *}$ D, Mohamed Saber ${ }^{2}$, Samir Gadow ${ }^{2}$ and Fikry Awad
}

\begin{abstract}
Environmental pollution from varied sources is now deemed as one of the most serious problems everywhere. Several pollutants, however, could be perceived by certain biological indicators, each one is used to identify assured single or a category of pollutants. The current review presents the use of biotas, i.e., plants, microorganisms, and animals, to perceive ecosystems pollutants. The most significant biological indicators are presented. The plant indicators described belong to higher plants; the microbial indicators were represented by bacteria, fungi, algae, planktons, lichens, helminthes eggs and enzymes and the animal ones were earthworms, macro-invertebrates, frogs $\&$ toads, insects and animal toxins.
\end{abstract}

Keywords: Biological indicators, Monitoring, Pollution, Terrestrial and aquatic ecosystem

\section{Introduction}

Environmental pollution, at the time being, is one of the foremost problems worldwide. Pollutants must be detected and remediated by several technological tools. Biological indicators are living organisms, i.e., plants, animals, and/or microorganisms, which are exploited to detect pollutants in a given ecosystem. They explore the life span or residence time of pollutants integrating past, current, and future ecosystem status. They are supportive, objective, straightforward, applicable at various scales, and reproducible. Naturally occurring biological indicators are regularly used to assess a given ecosystem detecting positive and negative changes therein. Khatri and Tyagi (2015) emphasized the significance of caring about the natural factors interacting with biological indicators such as light, moisture, temperature, and suspended solids. Chemical (Saber et al., 2016a) and physical (Zaghloul et al., 2019) pollutants indicators might oversight several irregular pollutant bursts. So, integration between biological, chemical, and physical pollutant indicators is tremendously demanded.

\footnotetext{
* Correspondence: alaazaghloul2008@gmail.com

${ }^{1}$ Soils and Water Use Department, National Research Centre, Cairo, Egypt Full list of author information is available at the end of the article
}

This current review article appraises the concept behind biological indicators, with particular emphasis on their potential use in assessing terrestrial and aquatic ecosystems pollution.

\section{Ecosystem pollution}

By definition, pollution is the introduction into a given ecosystem of substances or energy liable to cause several adverse impacts deteriorating health, harming biota, damaging structures or amenity, and/or interfering with the authentic uses of environment. Nowadays, the unrestrained human behavior led to anxious pollution problems in ambient air, aquatic, and soil ecosystems and food web as well. This became a hazard towards the continued existence of many biological communities and might ultimately jeopardize the survival of human race on earth planet. Many biologically active substances could act as pollutants; few of them might be without adverse impacts on living organisms at some concentration (Butterworth et al., 2001; Holt and Miller, 2010). Pollutants might be classified by their chemical composition and physical state or by their properties, i.e., solubility, biodegradability, reactivity, and/or by sectors, i.e., air, aquatic, terrestrial, or by source, i.e., fuel combustion, industry, or domestic. Almost all of these classifications are subjective, yet, the most regular classifications

\section{Springer Open}

(๑) The Author(s). 2020 Open Access This article is licensed under a Creative Commons Attribution 4.0 International License, which permits use, sharing, adaptation, distribution and reproduction in any medium or format, as long as you give appropriate credit to the original author(s) and the source, provide a link to the Creative Commons licence, and indicate if changes were made. The images or other third party material in this article are included in the article's Creative Commons licence, unless indicated otherwise in a credit line to the material. If material is not included in the article's Creative Commons licence and your intended use is not permitted by statutory regulation or exceeds the permitted use, you will need to obtain permission directly from the copyright holder. To view a copy of this licence, visit http://creativecommons.org/licenses/by/4.0/. 
of pollutants are those attendants with their biological, chemical, and physical properties. On the other hand, pollutants' classification on the basis of their functions is affiliated to the current biological and physiological knowledge. Generally, which system of these classifications is chosen evidently depends on the rationale for which the information is being brought together.

\section{Terrestrial and aquatic ecosystems pollution}

Terrestrial and aquatic ecosystems are complex heterogeneous bio-colloidal medium, therein physical, chemical, and biological phenomena apt to act towards a dynamic equilibrium. The fate of a given pollutant is directly governed by its ecological reactivity under various circumstances. Pollution is certainly one of the most vital traits of ecological degradation since the ecosystem is the ultimate reservoir of most pollutants; it is usually an outcome of insanitary habits, agricultural practices, mistaken disposal of wastes, and fallout from atmosphere (Jain et al., 2010). No wastes should be disposed in a terrestrial or aquatic ecosystem without having been previously analyzed, both chemically and biologically, in order to avoid the risk of impairing the ecosystem. Most wastes contain extensive loads of pathogens, potential toxic elements (PTEs), and emerging persistent organic pollutants (Hoballah et al., 2014 \& 2015 and Saber et al., 2014). The development of guide lines of controls should be based on field observations on the effect of the sub-lethal concentrations of pollutants on terrestrial and aquatic ecosystems. In response to disturbance or stress, ecosystem health has been defined in terms of ecosystem stability and resilience. Nevertheless, the magnitude of a response and time to return to the current state before pressure might serve as ecosystem health instruments (Khatri and Tyagi, 2015). A comprehensive thoughtful of the inclusive significance of biological indicators should be sustained upon a contemporary ecosystem concept.

\section{Biological indicators}

Biotas are commonly used to describe the features of a specific biosphere and are well recognized as biological indicators (Gaston, 2000 and Joanna, 2006) frequently used to study the severity of ecosystem changes (Gaston, 2000 and Marques, 2001).

The terminology "Biological Indicators" is an oversight term that describes all sources of biotic and abiotic reactions related to changes in a given ecosystem. Instead of simply working as measures of natural change, taxa are used to show the effects of natural changes in the environment, or changes in the ecosystem. They are habitually used to identify and signify negative or positive effects in natural environments. These could also be used to detect changes in ecosystems due to the occurrence of pollution that might affect the biodiversity therein. No single biotas between the 1.7 million species that currently documented on earth could satisfactorily indicate every type of disturbance or stress in all ecosystems (Holt and Miller, 2010). Always, established species and local disturbances in a given ecosystems are suitable for selecting the biological markers species or groups of species. Ecologists have recently established a comprehensive set of criteria for biotas to be deemed as worthy biological indicators.

Each entity in a biological system might functions as a biological indicator for its surroundings. Certainly, the strength of a given biological indicator always acts as an early warning signal for pollution. They are frequently used to detect the synergetic and antagonistic impacts of various pollutants and to diagnose expected harmful impacts of pollutants towards biota. An imperative criterion for the biological indicator is the prompt and correct response to pollution, fit for targeted purpose and ability to detect changes brought about by depraved management, wrong land use, pollution, and/or climate changes in a given ecosystem. Responses to biological indicators are essentially within a physiological context despite being in some cases contained by a complex nature. However, growth, nutrition, and reproduction are exceptions inasmuch as they are subject to direct observation; despite being among the most valuable biological indicators evidences. On the other hand, structural responses are the most visible of all but their exact use is the most problematic since they stand at the end of a process initiated by the causative pollutant. Needless to say that the different viable species of a community do not always reflect the same response to pollutants, nor do they respond to any pollutant at the same degree. Many ecosystems might be overviewed as a puzzle that is often difficult to assign well-marked symptoms that definite a given pollutant. For pollutants existing in an excessively low concentration, boring analyses with highly sensitive technologies are required to identify them at a prohibitive cost. Once identified, they should be linked with all potential biological hazards. Alternatively, a biological indicator's sensitivity range offers an image of pollutant rates that are biologically significant, no matter how small.

One major benefit of biological markers is their ability to exhibit the indirect biotic effects of pollutants when many physical or chemical investigations are unable to do so. Scientists now agree that biotas alone are the best predictor of how ecosystems will react to a stressor's invasion or occurrence, for example, an average tropical rainforest habitualizing almost 300 tree species per hectare and enumerating that species response to pollutants disturbance would be impractical. In addition, a clear signal of biological indication might be obscured by a 
disproportionate number of responses of divergent species, as some species might increase while others decrease. When incorporating all of a pollutant's direct and indirect effects, emphasis should only be put on sub-set biotas or single species to explain what is happening. This restricted approach makes more appropriate and cost-effective biological measures. Biological indicators often depend on the ecosystem's troublesome intricacies and use a representative and/or totaled reaction to provide a complex image of the ecosystem's state. There are numerous benefits of biological indicators that drove legislative authorities for their use and inclusion in several international accords. But species of biological indicators might be affected by factors other than disruption or stress, such as disease, parasitism, competition, and/or predation, which obscure the image of the causal mechanisms of change. The use of biological indicators is also limited to their ability as scale-dependent. For instances, fish might fail to indicate the biodiversity response to pollutants at a local insect community. In contrast, in their natural ecosystem, species of biological indicators typically have different habitat requirements than other species. The monitoring of ecosystems for specific biological indicators according to their habitat requirements could fail to protect rare species with different requirements. Finally, the overall goal of biological indicators is to use a single species, or a small group of biotas to evaluate the quality of a given ecosystem and how it changes over time, but this could be a gross oversimplification of a complex ecosystem. Nkwoji et al. (2010) reported that biological indicators continuously integrate knowledge from their ecosystem's genetic, physical, and chemical components and manifest as changes in individual fitness, population density, community structure, and ecosystem processes. Biological metrics distinguish between what is and is not biologically stable from a management point of view. Through biological criteria, the effect of human disruptions could be detected before doing anything to deter them is too late.

The ultimate goal of any remediation process should not only be to eliminate pollution, but also to preserve the ecosystem health. Consequently, when assessing the efficiency of a remediation technique, accurate biological health measures are required. Nowadays, biological indicators are exploited and endorsed by several organizations, e.g., the World Conservation Union, International Union for Conservation of Nature, as tools to handle biological monitoring. It seems reasonable to state that the limitations of biological indicators are obviously overshadowed by their benefits.

\section{Plants, animals and microorganisms indicators}

Biotas could often be used to estimate pollutant levels in their habitats indirectly. It might also be possible to track population density over time and notice changes that might result from changes in the ecosystem. A biological indicator is a living organism that always displays an indicative idea the ecosystem's health status. Many species are very susceptible to pollutants existing in their ecosystem, so if there are toxins, they might alter their anatomy, physiology, or behavior. Millions of the biota species were detected in most habitats in our earth. $\mathrm{Nu}$ merous plants, animals, and microorganisms are endowed tools for indicating pollutants in a given ecosystem. They have a major role in selecting the pest management practices in a given ecosystem as well as differentiating between the polluted and unpolluted ones. Recently, microorganism activities are extended to cover nitrogen mineralization, microbial diversity, and some functional fauna classes; the national and international quality monitoring programs include now biomass and respiration measurements.

\section{Plant indicators}

Abundant plant species, e.g., higher plants, lichens, and planktons, usually donate basic minutes about the wellbeing of a given ecosystem. Plants are very delicate tools for the prediction and recognition of ecosystems stresses. Recently, following industrialization and urbanization terrestrial and aquatic ecosystems pollution had been intensified (Joanna, 2006). Most plants promote useful estimation of the polluted ecosystem status, as they are immobile and easily strike a balance in their natural environment (Jain et al., 2010).

Higher plants Due to their immovability and lengthened existence, higher plants are subjected to many categorized ecosystem pollutants and hence often seem to be worthy biological indicators (Ernst, 2003). The effect of pollutants on plant arrays from morphological fluctuations to biochemical and/or cellular alterations is frequently noticed through the overall impacts on their growth, performance, and population intensity. On the whole, external vegetative symptoms are considered as the first biological indicator (Saber et al., 2015a). But generally, it would be necessary to confirm such assumptions with further botanical and/or chemical analyses (Bleeker et al., 2003). Most PTEs could be monitored by certain higher plants (Malizia et al., 2012).

Certainly, the quantitative response in plant growth is easier to recognize and express than the qualitative influences using the tolerance index (TI) which is calculated as follows:

\section{Tolerance index $=$ growth in polluted soil $/$ growth in unpolluted soil}

It might be simpler to differentiate between external and internal quality criteria when qualitative impacts are well-thought-out. External factors such as form, color, 
and taste are often measured as subjective parameters that oblige skillful surveillance. Now there are abundant biological plant symptoms following pollution such as changes in $\mathrm{pH}$ recognized after growing certain acidophytes, i.e., common ling (Calluna vulgaris), hair grass (Deschampsia Flexuose), or sunflower (Drosera rotundifolia); changes in nitrate content in ecosystems associated with growing wild barley (Hordeum murinum), French mercury (Mercurialis annua), or large nettle (Urtica dioica); and changes in total soluble salts content following growing certain plants such as the halophytes lead grass (Salicornia europeae), tripoly (Aster tripolium), and wild march beet (Statice limonium). Lower plants might be appropriate measurement for the quality evaluation of a metal plant extraction process (Hernández-Allića et al., 2006). In pot experiments, Saber et al. (2016a, b) measured the assessed the metal phytoextraction on the phytoremediation under $T$. caerulescens and detected increased values of biomass $C$, basal respiration, induced respiration of the substratum, and $\beta$-glucosidase production. The highest capacity of the test plant was registered in the phyto-extract of $\mathrm{Zn}$ from degraded habitats indicating the beneficial effect of metal-phyto-extraction on biological activity in a given ecosystem. T. caerulescens might help to improve their microbial and biochemical functionality.

Planktons Planktons are biotas habitually existing in most aquatic ecosystems and eventually grow intensively enough to swim against the currents. They are usually microscopic, often less than $1 \mathrm{in}$. in length, but they also include larger species like some crustaceans and jellyfish. Scientists classify plankton in several ways, including their size, type, and how long they spend drifting. Yet, the most basic categories divide plankton into two main groups: phytoplankton (plants) and zooplankton (animals). They are microbiota that live in huge aquatic ecosystems and are unable to swim against currents. Planktons are a crucial source of food to many small and large aquatic biotas. A significant biological development of planktons, combined with chlorophyll, takes place in aquatic ecosystems such as rivers, reservoirs, streams, and swamps. Offem et al. (2011) reported that in populations swimming around rivers and tides, planktons often fuse large amounts of energy and eventually pass to higher trophic levels. They are capable of integrating and usually used in determining the pollution status in a given aquatic ecosystem. Because planktons are highly susceptible to natural changes in diverse ecosystems, they are good indicators of aquatic consistency. Planktons could monitor aquatic ecosystems under high phosphorus and nitrogen existence as both pollutants inspire other biotas living in the aquatic body (Thakur et al., 2013). Plankton could be critical biotas for many living organisms in a given aquatic ecosystem as a health indicator. Saber et al. (2015b) stated that plankton could therefore be regarded as a measure of ecosystem sustainability as well as a primary food source for many species.

One of the predominantly known powerful plankton biological indicators is Cyanophyta that indicates rapid eutrophication of aquatic ecosystems via creation of bloom formations (Thakur et al., 2013).

Phytoplankton had been used in successful observations of aquatic ecosystem pollution as useful biological indicator. The connections between the growth rate and each of those variables could however be influenced by pollutants. In the event, for example, a colored, suspended solid lightcontaining industrial effluent could be filtered or absorbed resulting in a decline in growth rates. Phytoplankton are also a key source of pollutant transfers to humans, from marine to the high tropics. This group of biological indicators is known also as microalgae, they contain chlorophyll similar to terrestrial plants hence require daylight to live and develop. Most of them swim in the upper portion of aquatic ecosystems (Uttah et al., 2008; Malik and Bharti, 2012 and Hosmani, 2014).

\section{Microbial indicators}

Within marine and coastal habitats, micro-organisms are often used in testing ecosystem pollution (Gerhardt, 2002), as far as their rapid growth microorganisms always respond even at low pollutant rates and exhibit imperative signs of ecosystem changes. Due to their abundance in varied ecosystems, they are straightforward to and readily available to detect pollutants (Khatri and Tyagi, 2015). There are six specific well-defined criteria for the selection of microbial indicators. Microbial biotas are reliably and precisely exiting across a wide range of ecosystems. Microbial toxins, particularly in aquatics ecosystems, could be easily monitored and used as pollution indicator. Nonetheless, Butterworth et al. (2001) reported that microbiota are very easy to track relative to other standard studies; their regulation, nonetheless, could only reflect improvements in their communities due to toxins. The Microbial Consortium has a high capacity in modifying their operation levels, biomass, and group composition to manage ecosystem pollutants. These parameters are especially important in assessing the quality of a given ecosystem. Bioluminescent bacteria are commonly employed to identify ecosystem toxins as microbial markers and could be implemented in many respects.

\section{Bacterial indicators}

Bacterial indicators are groups or species of bacteria whose presence in an ecosystem, above certain numerical limits, indicates their contact to pollutants. Bacteria for sure have a value in assessing pollution problems in 
varied ecosystems (Kalkan and Altuğ, 2015). The effectiveness of using bacterial indicators is governed, however, on the one hand, by the relation between the existing pollutants and their associated microbial flora as well as with the type and scope of questions raised by the researcher, i.e., diagnostic accuracy and requirements (Sumampouw and Risjani, 2014). An imperative bacterial biological indicator, despite its high experimental error, is the determination of total bacterial counts. But it should be born in mind however that an absolute total bacterial count is virtually never obtained, because it is not that affluent to find a single culture medium that all bacteria in a certain ecosystem could develop their colonies. Individual bacterial counts, on the other hand, are established on selective medium best suited in each case. Anaerobic mesophilic bacterial counts as well as Salmonella typhimurium and clostridium sp. in a given ecosystem could serve as a biological indicator for aquatic logging conditions. Coliforms include numerous aerobic and anaerobic facultative bacteria able to ferment lactose with gas formation within $48 \mathrm{~h}$ incubation at $37^{\circ} \mathrm{C}$, are widely used as a biological indicator. Fecal coliforms are those organisms among coliforms that are able to grow and ferment lactose at temperatures higher than normal $\left(44-45{ }^{\circ} \mathrm{C}\right)$. They comprise mostly a high proportion of E. coli types I and II and are thus useful as biological indicators for contamination of relatively recent fecal origin (Saber et al., 2015b).

In recreational aquatic ecosystems, fecal coliforms are more useful as biological indicators than as total coliforms, which include bacterial specie naturally found on plant and in soil. Some fecal coliform species have no fecal origin such as Klebsiella pneumoniae.

Along many decades, fecal E. coli was used a biological indicator for pollution with intestinal bacteria at ElGabal El-Asfar sewage farm soils in Cairo. Fecal coliforms survived in the soil layer up to 60 days, and hence, no vegetables eaten raw should be grown in a sewage farm. In microbiology, enterococci mean Streptococcus faecalis and Streptococcus faecium. Both species have their natural habitat in the intestinal tract of man and animal and might have a distinctive role as biological indicator for pathogens in food produced in a sewage farm.

Halophile bacteria with a high ability to grow under high salt concentration are good biological indicators in detecting salinity problems in a given soil ecosystem. If it is intended to irrigate with low-quality aquatic, salts should be checked periodically, and here, the total count of halophile bacteria might be considered a good biological indicator for salinity.

Bacteria are always found in dense quantities in most ecosystems and are easy to sample than other biotas. None of the biological indicators currently employed match exactly the needed criteria; furthermore, the use of biological indicators is only significant when costs are deliberated.

Bacterial indicators include several types of bacteria, such as Escherichia coli and Enterococci that are habitually used to detect and estimate the level of pollution in varied ecosystems. In most cases, they are not dangerous to human health but are used only to indicate pollutant risks. Ecosystem samples are usually transferred onto narrow pore-sized membranes, and a specific agar is put in the membrane. In order to prevent the development of too few or too many colonies on a plate, it is often important to adjust the amount of water sample filtered. Bacterial colonies are counted after 24 to $48 \mathrm{~h}$ and colony units per $100 \mathrm{~mL}$ (cfu/100 mL) are recorded. Sanitation programs often test aquatic ecosystems for the presence of fecal coliforms to ensure water safety. Such testing is done by several methods involving water sampling or passing enormous amounts of water through a filter to sample bacteria and grow them on selective media such as MacConkey. Approximately 100 billion $\left(1 \times 10^{11}\right)$ bacteria compose every gram of human feces and include some pathogeny bacteria such as Salmonella sp., Campylobacter sp., and gastroenteritis associated habitually. In addition, feces could include pathogens, protozoa, and parasites. Such fecal material enter ecosystems from a wide variety of sources such as aquatic waste, processing plants, poultry manure, sanitary waste dumps, septic systems, wastewater treatment plants, sewage sludge, pets, and the wild. Fecal pathogens could cause disease if sufficient amounts are absorbed. Low existence of pathogens in a given ecosystem renders them difficult to be individually verified. Because of their short generation time and rapid response to ecosystem pollution, micro-organisms are excellent fast and short-term biological indicators. Recently, a gross pollution detector was developed for general purpose monitoring a range of pollutants at a laboratory scale by measuring bacterial respiration and survival in ecosystems.

When exposed to certain pollutants such as cadmium or benzene, some bacteria secrete new stress proteins that might be used as an early warning to detect changes in the levels of pollution in a given ecosystem. On the other hand, coliform bacteria must not persist in the ecosystem for long periods of time following efflux from the intestine and their occurrence should be closely correlated with pollution fecal organisms as a biological indicator organism need not be pathogenic. Some noncoliform bacteria, such as Streptococcus bovis and certain Clostridia sp., might also be used as an index of fecal pollution in terrestrial and aquatic ecosystems. The classification of the microbial biomass might be determined through microbial behaviors such as breathing, mineralization of $\mathrm{C}$ and $\mathrm{N}$, biomic $\mathrm{N}_{2}$ fixation, and 
enzymes. Some microbial behavior, e.g., biomass-specific breathing, seems to be more sensitive than its single action or population rate (Aslam et al., 2012). There might also be some kind of "global regulation" metrics, e.g., biomass as a proportion of organic matter. Such methods could be built to test whether toxins without costly and long-running field routes change the natural ecosystem.

Recently, other new technological solutions to emission research in molecular biology (e.g., genetic fingerprinting) would be useful. In order to find biological bacterial markers in aquatic ecosystems, immunologic approaches of monoclonal antibodies might be used. To prevent the identification of dead cells, some precultivations on select medium would preface detection. ELISA antibody technique is developed to make it possible to detect coliform micro-colonies easily with the naked eye.

The approaches focused on gene sequence rely on the difference between common gene sequences and different strains of a given species. The gene sequence-based approaches commonly used to identify some strains of bacterial markers include polymerase chain reaction (PCR) and fluorescence in situ hybridization (FISH).

\section{Fungal indicators}

Faunal communities are extremely distributed in both terrestrial and aquatic ecosystems and play an imperative role in their functions. Molds such as Trichoderma sp., Exophiala sp., Stachybotrys sp., Aspergillus fumigatus, Aspergillus versicolor, Phialophora sp., Fusarium sp., Ulocladium sp., Penicillium sp., Aspergillus niger, Candida albicans, and certain yeasts are frequently used as biological indicators for contaminants. Ecosystem incidents are effectively monitored using varied fungal indicators species on the basis of their resistance to given ecological variability's. The moss Hylocomium splendens was habitually used as natural fungal indicator for PTEs in the remote tundra ecosystems northwestern Alaska (Hasselbach et al., 2005). They measured the PTE contents in the moose tissue at varied distances from the road and found them higher in samples adjacent to the road and were reduced with time.

\section{Algal indicators}

Hosmani (2013) stated that one or more algae might be efficaciously used as pollution biological indicators and confirmed that a composite rating of algae such as $\mathrm{Eu}$ glena sp., Chlamydomonas sp., Scenedesmus sp., and Chlorella sp. were successfully used to indicate pollutant in aquatic ecosystems. In most cases, polluted aquatic ecosystems would host few algae, with one or two being the most dominant forms. Dokulil (2003) and Zancan et al. (2006) confirmed that the normal distribution of diatoms in polluted aquatic ecosystems is presently well known.

The interaction between algae and the other components in terrestrial ecosystems had received little attention as far as there is still a general lack of awareness about their existence in such terrestrial ecosystems. One reason for the scarcity of data on terrestrial ecosystems algae is the difficulty of examining their existence therein, yet it is expected that many algae could survive in the terrestrial ecosystems particularly in their resting stages (Singh et al., 2013). Both nutrients status in terrestrial ecosystems as well as the $\mathrm{pH}$ value are susceptible to considerable alternation under pollution disorders, the $\mathrm{pH}$ value always shifts to the acidic side, and nutrients are depleted. Dokulil (2003) stated that blue-green algae might be used as biological indicators for perceiving the changes in $\mathrm{pH}$ value in different ecosystems; however, they are enormously rare below pH 5 . Jain et al. (2010) reported that increases in algal species diversity, like Euglena clastica, Phacus tortus, and Trachelon anas, always suggest marine ecosystem degradation. The blooms of algae in lakes and rivers are often used to demonstrate large increases in nitrates and phosphates.

One of the foremost problems always coupled with ecosystem pollution is the incidence of PTEs. Algae had been habitually engaged as good biological indicators of PTEs through different approaches, yet none of these approaches had been developed so well that it could be routinely pragmatic. Numerous studies on PTEs pollution benefited from algae as a biological indicator mainly due to interest rather than algae are more suitable organism for that. Most faced data interpretation might eventually prove to be straight forward, but much more information are still needed about PTEs accumulation by the potentially most useful algae Cladophora sp., Lemanea, Enteromorpha, and Nitella sp.

In recent years, microalgae have been shown to be sensitive to pollutants in different ecosystems. The most famous microalgae, Euglena gracilis, is a motile fresh aquatic photosynthetic flagellated microalga tolerant to acidity, sensitive to pollutants, and rapidly respond to stresses particularly those related to PTEs and persistent organic pollutants. Distinctive responses of this microalga appear in inhibiting movement and changing orientation parameters. Euglena gracilis is easy to handle and useful in eco-toxicological assessments. It has a very pollutant-sensitive gravitational direction.

Lichens Lichens are mutualistic associations of symbiosis microorganisms belonging to Cyanobacteria composed from algae and fungi as well as Bryophytes (liverworts) mostly occurring as crusty continuous patches of bushy growths on trunks of trees and rocks 
and bare ground. Lichens are widely used as biological indicators due to their effectually respond to ecological pollution in forest ecosystems, particularly pollution arising from the increases in the level of $\mathrm{SO}_{2}$ and/or $\mathrm{N}_{2}$ that could be specified by the vanishing of lichen in forest ecosystems (Gerhardt, 2002). Lichens are considered as powerful biological indicators due to their high surface that further support their use as biological indicators able also to capture pollutants particularly from air (Holt and Miller, 2010).

Genetically engineered species of algae always react to varied levels of toxicity in a given ecosystem. For example, a sort of genetically engineered grass that if toxins are present, grows in another color. They are very sensitive to the existence of PTEs, $\mathrm{SO}_{2}$, and toxic gases in their ecosystems and hence might be extinct in industrial region where just green algae might be found. If their air is cleansed, the lichens become shrubby, hairy, and leafy. Some species of lichen might tolerate very high levels of PTEs and radioactive metals. .

Enzymes Enzymatic activities are considered to be sensitive to pollutants and had been suggested as biological indicators to measure the degree of degradation in a given ecosystem. It was repeatedly witnessed that the enzyme lysozyme improved dehydrogenase activity that determine respiration inhibition. When this tool was used, the effect of certain pollutants, e.g., mercury and cyanide, could be assessed. The production of enzymes in polluted ecosystems varies from 37 to $260 \%$ for phosphomonoesterase, from 16 to $250 \%$ for $\beta$-glucosidease, from 28 to $194 \%$ for urease, and from 24 to $250 \%$ for dehydrogenase. In all situations, though, the degree of degradation is measured by the ratio $\mathrm{Nc} / \mathrm{Nk}$ where $\mathrm{Nk}$ is nitrogen from Kjeldahl and Nc is the microbial biomass potential of $\mathrm{C}$ and mineralization of nitrogen throughout conjunction with some enzymatic activities. This ratio always exhibits all the features of a strong emission measure, in particular the impact of the pollutant and the deterioration of the sites. This means that the ecosystem depletion quantification should include details on its enzymatic activities and information on some other biochemical properties as well.

\section{Animal indicators}

Dissimilarities in animal populations always designate harmful changes initiated due to ecosystem pollution. Changes in animal populations often refer to the relationship between animal populations and food sources; if food resources were limited and could not fulfill population requirements, a decrease in population intensity would follow (Jain et al., 2010). Animal indicators also help to detect the amount of toxins in animal tissues (Joanna, 2006). The many fold advantages of animal biological indicators always outweighed their restrictions. Animal biological indicators are useful, objective, straightforward, and reproducible. They could be used at various scales to assess the changes taking place in a particular ecosystem.

Earthworms Gao and Luo (2005) summarized the function earthworms as biological indicators in their existence in a given ecosystems that reflects the degree of its pollution as a whole. In the ecotoxicology risk assessment, earthworms serve as a significant indicator for potential pollutants damaging the ecosystem and earthworms also act as an early warning system in monitoring changes related to pollution. The main resistance mechanisms of earthworms to some PTEs such As, $\mathrm{Pb}$, $\mathrm{Zn}, \mathrm{Cu}$, and $\mathrm{Hg}$ are elaborated by its lipid anti-oxidative enzyme system that helps the relieve oxidation stress and is compartment and immobilization of PTEs. Chelating and detoxing mechanisms are triggered when PTE activity is present in both lysosome and cell plasmid. The potential of earthworms in enhancing ecosystems bioremediation is done through improving their physical and chemical characteristics, activating microorganisms and changing bioavailability of pollutants. In order to measure rates of terrestrial habitat pollutants, shifts in the activity of earthworm nervous systems are used. The numbers of earthworms in a given ecosystem could also be used to indicate its health status.

Macro-invertebrates Marine invertebrates called benthos or macro-invertebrates are often located near the ground in the aquatic ecosystems. Such kinds of biological markers might be especially powerful for aquatic shed safety, since they are easy to distinguish in labs, live regular over a year, have limited mobility, and are environmentally friendly integrators (Khatri and Tyagi, 2015). The biological health indicators in marine and earthrelated habitats are beneficial and expedient. These are almost always available and could be collected and categorized quickly. The resilience of the macro-invertebrate species also allows for objective evaluation of the circumstances of the ecosystem. Aquatic emissions and destruction of the habitats due to human activities such as systematic harvesting and wilderness in tropical forests ecosystems are typically measured by tolerance levels.

Frogs and toads Frogs are good biological indicators for the quality and changes in a given ecosystem. They are affected primarily by shifts in their fresh marine and terrestrial ecosystems. The biological indicators of pollutant accumulation in a given ecosystem are habitually used as amphibians, particularly anurans consisting of frogs and toads. Anurans are responsive to changes to their ecosystem and ingest toxic chemicals by their skin and 
larval gill membranes. They are inadequately capable of detoxifying pesticides which they ingest, inhale, or consume from contaminated foods. This permits accumulation in their bio-systems of residues, especially organochlorine pesticides. They might also consume toxic chemicals with their permeable skin that makes them a model for evaluating the impact of ecological influences that could contribute to decreases in the amphibian population. These factors allow them to follow ecosystem changes, eco-toxicological trials, and human demands to the environment as biological indicators. For contamination research such as the environmental effect of agricultural chemicals, anurans are widely used as biological markers. An analysis of their area abundance and assessment of their locomotive ability and of any abnormal morphological changes that are deformations and abnormalities in development is performed to study the ecosystems where they live. Declines in anurans and malformations might suggest that ultraviolet light and parasites are more vulnerable. The diverse biotas lifecycles in terrestrial and aquatic allowed breeding many anurans particularly those sensitive to pollutants. The results most frequently mentioned in conjunction with chemical reactions involve morphological and physiological modifications during the embryonic development. Exposure symptoms might contribute to reduced body length, lower body weight, and limb and other organ malformations. The slow growth, late morphological shifts, and limited metamorphic sizes increase the risk of mortality and predation exposures.

Insects Disturbances of some species could be used as a parameter of analyses about the levels of change in a given ecosystem. Insects are the furthermost abundant biotas in most ecosystems. They are more strictly and quickly affected by pollutants in their ecosystem and hence considered as moral biological indicators for pollution in both aquatic and terrestrial environments. Insects are responsible for many processes in the ecosystem, and their loss always have negative effects on entire biological communities. Thus, a strong understanding of insect responses to pollutants is a must to value functional consequences of pollutants (Nichlsa et al., 2007). Through changes in their population and behavior, it is possible to estimate what the current degradation future consequences in their ecosystem. Many insects are habitually used for biological indicators because they are most frequently found in varied ecosystems and they could be easily sampled with pitfall traps. Tylianakis et al. (2006) stated that insect biological indicator became particularly useful as they represent more than half of all biotas species in a given ecosystem. daRocha et al. (2010) stated that any insect suggested to be used as biological indicators should be easily captured and transported, having high ecological faithfulness, fragile to minute changes, their behavior is easily observed and measured, having a close correlation with the preselected abiotic variables, respond hastily to ecosystem changes, have a short life cycle, have high sensitivity for detecting early changes in their ecosystem and provide information without interruption of the extent damage caused by ecosystem alteration due to pollution. The use of some species of Coleoptera (beetles), Homoptera (bugs), and Diptera as biological indicators was restricted due some taxonomical and sampling difficulties, lack of reliability on those already described, and taxonomic difficulty, particularly in their larval stage. Hardersen (2000) reported that several aquatic insects such as Odonata sp. (dragonflies); families Gyrinidae, Dytiscidae, Hydrophilidae (Coleoptera), Notonectidae, Veliidae (Heteroptera), and Plecoptera; and orders Diptera and Ephemeroptera have high adaptive capacity potential as biological indicators. However, insects are less used as metal pollution biological indicators, despite species of the genus Halobates is suitable to indicate $\mathrm{Cd}$ and $\mathrm{Hg}$ (Nummelin, 2007). The order Coleoptera particularly beetle's species (Coleoptera: Scarabaeidae) represents approximately $20 \%$ of the total diversity of arthropods in terrestrial ecosystems (Davis, 2000). Moths and butterflies (Lepidoptera), besides having basic necessities and ecological faithfulness in temperate and tropical regions, are very sensitive to changes in their ecosystems.

da-Rocha et al. (2010) mentioned that some lepidopteran groups are used as ecosystem pollution indicators for PTEs and $\mathrm{CO}_{2}$ in locations close to industrial areas and even within urban areas. Presence and consequences of $\mathrm{Cu}, \mathrm{Fe}, \mathrm{Ni}, \mathrm{Cd}$, and $\mathrm{H}_{2} \mathrm{SO}_{4}$ were detected by pupae of different Geometridae and Noctuidae species, Eriocraniidae population, cycle duration, and newly hatched larval mortality rate from butterflies (family Nymphalidae). Collembola sp. are primitive insects very sympathetic to changes in terrestrial ecosystems which could detect pollution by PTEs. Many studies have demonstrated deformities in larvae from several genera from the family Chironomidae (e.g., Procladius, Chironomus, and Cryptochironomus), and the results indicated that the abnormalities are strongly associated with polluted sediments. Members of Gerridae family were used in detection of different iron and manganese concentrations, but they seemed to be less suitable for nickel and lead (Nummelin et al., 2007). Some of the Sarcophagidae family members are good markers for PTEs, asbestos fibers, and industrial toxins. According to fly heterogeneity, however, care must be taken when using chemical markers of certain types of flies. The Syrphidae family is one of Diptera's main groups with wide-range and wellestablished taxonomy and their larvae require different conditions in their ecosystem. The insecticides 
concentrated in bees cells are considered as biological markers and generally regarded as the most important elements of their intensity and population size. In particular Apis mellifera are regarded as effective biological markers as far as they show a high mortality rate of ecological chemical loss and catch particles that could later be observed in air or flowers (Ghini et al., 2004). daRocha et al. (2010) confirmed that cultivated regions or reforested areas with some diversity of plant species exhibited high insect species diversity and greater ecological stability, where the competition for resources is intense, preventing the prevalence of few dominant species. They added that the explanations for species loss in agricultural ecosystems were due to changes in microclimatic conditions, foraging activities, nesting sites, and reducing food availability by agrochemical use. In forest ecosystems, the imbalance begins with native vegetation replacement that normally has high insect diversity in homogeneous plantation areas, where ecological balance is fragile and insect diversity is reduced. Therefore, the number of harmful insect species is quite high and frequently occurring population booms, especially of defoliator lepidopteran. Reforestation is usually located in nutrient-poor soils, and at certain times of year, the trees are exposed to water stress, becoming highly susceptible to attack by insects. During this period, there might be population booms of aggressive and prevalent insects.

Ants are habitually used as are very sensitive biological indicators having a key role in the recovery of degraded ecosystems. Ameliorations showed strong tolerance to contaminants (radioactive and chemical chemicals) because about $10 \%$ of humans are subjected to harmful pollutants outside the nest. It was used to calculate the quantities of toxins in boreal forests and is now used to track threatened habitats. Bees have been known as one of the biological metrics most flexible and effective. These are used to track PTEs, toxic contaminants, and toxins (Urbini et al., 2006) in urban ecosystems, radioactivity following Chernobyl accidents, pesticides, and herbicides.

Wasps are vulnerable to the harmful biological accumulation at the top of the food chain. As Pb could accumulate up to 36 times the adult body with its mass larvae, their genus spices are promising ones in the detection of $\mathrm{Pb}$ pollution.

According to da-Rocha et al. (2010), termites are important decomposers in terrestrial ecosystems. Their activity increases infiltration capacity and leads to water retention and higher productivity. In agricultural, pasture, and reforestation areas, they are not always perceived because their nests are underground, and their presence is only noticed by the damage they cause to plants.

Aphids are pollution indicators, because they show an increase in their population density when feeding on hosts exposed to ecosystems with high $\mathrm{CO}_{2}$ concentrations.
However, studies did not show significant correlation between $\mathrm{CO}_{2}$ increase and Homoptera population density. They added that this class of insects include many possible members, including some of the Coleoptera orders, Diptera, Lepidoptera, Hymenoptera, Hemiptera, Isoptera, or other, that could be employed as biologically specific markers.

Zooplankton Zannatul and Muktadir (2009) reported that zooplanktons are microscopic animals that exist near the surface of the aquatic ecosystems and their movement depends upon tides and currents. They feed on phytoplankton, marine snow, and bacterial planktons. As biological indicators, zooplanktons play a key role and help to assess the level of contamination in aquatic ecosystems. These are the main food source for many other marine species in fresh aquatic ecosystems in conjunction with shrimp. Aquatic efficiency, eutrophication, and fresh water body growth are important for the development of zooplanktons. The weather fluctuations greatly influence zooplanktons. Ramchandra et al. (2006) and Zannatul et al. (2009) noted that the capacity of zooplankton as biological indicators is strong when associated with some other biotic parameters, e.g., food shortage, predation, and competitiveness, affecting their production as well as to some abiotic elements like temperature, saltiness, stratification, and pollutants. They also indicated that Trichotria tetrat, Alona guttata, Moscyclopesedex, Cyclips, and Aheyella could be utilized as pollution indicators as they were found in the aquatic ecosystems rich in phosphorus and PTEs. Ramchandra et al. (2006) stated that the development of zooplankton was always restricted with phosphorous and PTEs as well as with high aggregate alkalinity, hardness, and high conductivity $\left(130 \mathrm{~ms} \mathrm{~m}^{-1}\right)$ in the aquatic ecosystem. In India, seasonal zooplankton intensities exhibited their abundance in the rainy seasons, and their decrease in summer seasons is due to high temperatures. The dominating communities of zooplanktons are Copepods (Cladocer), Rotifer, and Ostrocoda (Zannatul and Muktadir, 2009).

Animal toxins Changes taking place in animal populations, weather increases or decreases, could indicate ecosystem pollution. In animal physiology, the morphology and conduct of the organism at population level could be articulated in association with stress-induced sublethal effects. Such sub-lethal responses could be very useful as "early warning signs" to determine how the community of a given ecosystem would respond more. The accumulation of pollutants in animal tissues, the pace at which deformations occur in animal populations, the actions in the field or in laboratory, and improvements in human physiology might be controlled by 
pollution and other stressors through assessing one of the several variables in animals.

For the testing purposes of soil pollution, a number of biological products are proposed. It should be noted that under all relevant conditions widespread calibration of soil pollution should be applied. Only qualitative knowledge on pollution levels is possible through use of one of the most relevant biological criteria.

\section{Conclusions}

In this work, the importance of biological indicators for monitoring pollution was documented along two decades ago. A diversity of biological properties had been proposed for monitoring purposes. The significance of particular biological monitoring could be inferred from the frequency of their use in various national and international programs. It should be mentioned that widespread calibration should be applied under all relevant conditions. The use of even one of the most suitable biological parameters will yield only qualitative information on pollution levels.

\section{Abbreviations}

EPA: Environment Protection Agency; PTEs: Potential toxic elements; Nk: Kjeldahl nitrogen; Nc: A function of microbial biomass

\section{Acknowledgements}

Thanks to the authorities of the National Research Centre for giving every possible help.

\section{Authors' contributions}

SG cared about the biological indicators of heavy metals in soil. AZ, FA, and MS clarified the relationship and the fates of pollutants in relation to soil properties. MS also revised the whole final edited manuscript after the writing. All authors contributed equally in the all article steps, wrote the paper, and approved the final manuscript.

\section{Authors' information}

Dr. Alaa Zaghloul Emurutis Res. Prof. at National Research Centre, Dokki, Giza, Soils and Water Use Department; Agricultural and Biological Division. Dr. Mohamed Saber Former Dean of the Agricultural and Biological Institute, NRC and Emurutis Res. Prof., Department of Agricultural Microbiology; National Research Centre, Agricultural and Biological Division.

Dr. Samir Gado is an Associated Res. Prof. at National Research Centre, Dokki, Giza, Department of Agricultural Microbiology, Agricultural and Biological Division.

Prof. Dr Fikry Awad Emurutis Res. Prof. at National Research Centre, Dokki, Giza, Soils and Water Use Department; Agricultural and Biological Division.

\section{Funding}

This work was funded by the National Research Centre.

\section{Availability of data and materials}

Not applicable

Ethics approval and consent to participate

Not applicable.

\section{Consent for publication}

Not applicable.

\section{Competing interests}

The authors declare that they have no competing interests.

\section{Author details}

${ }^{1}$ Soils and Water Use Department, National Research Centre, Cairo, Egypt.

${ }^{2}$ Agricultural Microbiology Department, National Research Centre, Cairo, Egypt.

Received: 16 April 2020 Accepted: 17 July 2020

Published online: 28 July 2020

\section{References}

Aslam M, Verma DK, Dhakerya R, Rais S, Alam M, Ansari FA (2012) Biological indicators: a comparative study on uptake and accumulation of heavy metals in some plant's leaves of M.G. road, Agra City, India. Res J Environ Earth Sci 4: 1060-1070

Bleeker PM, Schat H, Vooijs R, Verkleij JAC, Ernst WHO (2003) Mechanisms of arsenate tolerance in. Cytisus striatus New Phytol 157(10):33-38

Butterworth FM, Gunatilaka A, and Gonsebatt ME (2001) Biomonitors and biomarkers of environmental change. Kluwer academic/plenum publishing, New York, Vol II. Presentation/Presentación and Abstracts." Revista Internacional de Contaminación Ambiental 17.1: 53-63.

da Rocha J, Almeida J, Durval A (2010) Insects as indicators of environmental changing and pollution: a review of appropriate species and their monitoring. HOLOS Environ 10:1519-8634

Davis A (2000) Does reduced-impact logging help preserve biodiversity in tropical rainforest? A case study from Borneo using dung beetles (Coleoptera: Scarabaeoidea) as indicators. Environ Entomol 29:469-473

Dokulil MT (2003). Algae as biological bioindicator. Bioindicators and Biomonitors, Markert BA, Breure AM, and Zechmeister HG, Editors. Elsevier Sci. LTD

Ernst WHO (2003). Trace Metals and other Contaminants in the Environment, Chapter 12. The use of higher plants as biological indicators. 6: 423-463.

Gao Y and Luo Y (2005). Earthworms as biological indicators of soil pollution and their potential for remediation of contaminated soils. EPA, NCEA, HERO 42: 140-148.

Gaston KJ (2000) Biodiversity: higher taxon richness. Prog Phys Geogr 24:117-127

Gerhardt A (2002). Biological indicators species and their use in bio monitoring. Environmental Monitoring I. Encyclopedia of life support systems. UNESCO ed. Oxford (UK): Eolss Publisher.

Ghini S, Fernandez M, Pico Y, Marin R, Fini F, Manes J, Girotti S (2004) Occurrence and distribution of pesticides in the province of Bologna, Italy, using honeybees as bioindicators. Arch Environ ContamToxicol 47:479-488

Hardersen S (2000) The role of behavioural ecology of damselflies in the use of fluctuating asymmetry as a bioindicator of water pollution. Ecolog Entomol 25:45-53

Hasselbach L, Ver Hoef JM, Ford J, Neitlich P, Crecelius E, Berryman S, Wolk B, Bohle T (2005) Spatial patterns of cadmium and lead deposition on and adjacent to National Park Service lands in the vicinity of red dog mine, Alaska. Sci Total Environ 348:211-230

Hernández-Allica J, Becerril M, Zárate O, Garbisu C (2006) Assessment of the efficiency of a metal phytoextraction process with biological indicators of soil health. Plant Soil 281:147-158

Hoballah E, Saber M, Matter I, Zaghloul A (2014) Bioremediation of polychlorinated biphenyl (PCBs) in a sewaged soil by certain remediative amendments followed by phytoremediation. Res J Pharm Biolog and Chem Sci 3:91-103

Hoballah E, Saber M, Matter I and Zaghloul A (2015). Bioremediation of polyaromatic hydrocarbons (PAHs) in a sewaged soil by certain remediative amendments followed by phytoremediation. 8th Ann Inter Symp on Agric Res, 13-16 July 2015, Athens, Greece

Holt EA, Miller SW (2010) Biological indicators using organisms to measure environmental impacts. Nature. 3:8-13

Hosmani SP (2013) Fresh aquatic algae as indicators of aquatic quality. Univers J Environ Res Technol 3:473-482

Hosmani SP. (2014). Freshwater plankton ecology: a review. Management \& Technology 3: ISSUE 8 [Online ISSN 2320-0073]

Jain A, Singh BN, SI S, Singh HB, Singh S (2010) Exploring biodiversity as biological indicators for aquatic pollution National Conf. On biodiversity, development and poverty alleviation; Uttar Pradesh. Uttar Pradesh State Biodiversity Board, Lucknow (India)

Joanna B (2006) Biological indicators: types, development, and use in ecological assessment and research. Environ Bio-indicators 1:22-39 
Kalkan S, Altuğ G (2015) Bio-indicator bacteria \& environmental variables of the coastal zones: the example of the Güllük Bay, Aegean Sea, Turkey. Mar Pollut Bull 15(95):380-384

Khatri N, Tyagi S (2015) Influences of natural and anthropogenic factors on surface and ground aquatic quality in rural and urban areas. Front Life Sci 8: 23-39

Malik DS, Bharti U (2012) Status of plankton diversity and biological productivity of Sahastradhara stream at Uttarakhand, India. J Appl Natural Sci 4:96-103

Malizia D, Giuliano A, Ortaggi G, Masotti A (2012) Common plants as alternative analytical tools to monitor heavy metals in ecosystem. Chem Cent J 6:1-10

Marques JC (2001) Diversity, biodiversity, conservation and sustainability. Sci World J 1:534-543

Nichlsa E, LarsenB T, Spectora S, Davise AL, Escobar CF, Favilad M, Vulinece K (2007) Global dung beetle response to tropical forest modification and fragmentation: a quantitative literature review and meta-analysis. Biol Conserv 137:1-19

Nkwoji JA, Igbo JK, Adeleye AO, Obienu JA (2010) Implications of biological indicators in ecological health: study of a coastal lagoon, Lagos, Nigeria. Agric Biol J Noth Am 1:683-689

Nummelin M, Lodenius M Tulisalo, E Hirvonen H, and Alanko T (2007). Predatory insects as bioindicators of heavy metal pollution. Environ Pollution 145: 339347.

Offem BO, Ayotunde EO, Ikpi GU, Ochang SN, and Ada FB (2011). Influence of seasons on water quality, abundance of fish and plankton species of Ikwori Lake, south-eastern Nigeria. Fisheries and Aquaculture J.: FAJ-13.

Ramchandra TV, Rishiram R and Karthik B (2006). Zooplanktons as Biological Indicators: Hydrobiological investigation in selected Bangalore Lakes. Technical report 115

Saber M, Abouziena HF, Hoballah E, Soad El-Ashry and Zaghloul AM (2015b). Phytoremediation of potential toxic elements in contaminated sewaged soils by Sunflower (Helianthus annuus) and Corn (Zea mays L.) plants. $12^{\text {th }}$ Inter Phytotechnology Conf., Manhattan, Kansas, USA, 27-30 September (2015)

Saber M, Soad El-Ashry, Nizinski J, Montoroi JP, and Zaghloul AM (2015a). Chemical characterization of sewage effluent repetitively used in arid soils irrigation. $12^{\text {th }}$ Inter Phytotechnology Conf, Manhattan, Kansas, USA, 27-30 September (2015).

Saber M, Hoballah E, Soad El-Ashry, Abouziena HF. and Zaghloul AM (2014). Remediating potential toxic elements in sewaged soils using novel biotechnology. Inter Conf Chem and Environ Sci Res. 17-18 September, Park Royal Penang Resort, Malaysia.

Saber M, Hoballah E, Soad El-Ashry, Abouziena HF, and Zaghloul AM (2016b). Bioremediation of soil irrigated with sewage effluent Saber M, Abouziena HF, Wafaa M Haggag, Hoballah E, and Zaghloul A (2016). Potential toxic elements phytoremediation-Review". Res J Pharm, Biol Chem Sci 7 issue 2: 1148-1157.

Saber M, Hoballah E, Ramadan R, El-Ashry S, Zaghloul AM (2016a) Kinetic assessment of potential toxic elements desorption from contaminated soil ecosystems irrigated with low quality aquatic. Inter J Soil Sci 11:71-78

Singh UB, Ahluwalia AS, Sharma C, Jindal R, Thakur RK (2013) Planktonic indicators: a promising tool for monitoring aquatic quality (early-warning signals). Eco Environ Cons 19:793-800

Sumampouw OJ, Risjani Y (2014) Bacteria as indicators of environmental pollution: review. Inter J Ecosystem 4:251-258

Thakur RK, Jindal R, Singh UB, Ahluwalia AS (2013) Plankton diversity and aquatic quality assessment of three fresh aquatic lakes of Mandi (Himachal Pradesh, India) with special reference to planktonic indicators. Environ Monit Assess 185:8355-8373

Tylianakis J, Veddeler D, Lozada T, López RM, Benítez P, Klein AM, GHJ K, Olschewski R, Veldkamp E, Navarrete H, Onore G, Urbini A, Sparvoli E, Turillazzi S (2006) Social paper wasps as bioindicators:a preliminary research with Polistes dominulus (hymenoptera: Vespidae) as a trace metal accumulator. Chemosph. 64:697-703

Urbini A, Sparvoli E, Turillazzi S (2006) Social paper wasps as bioindicators: a preliminary research with Polistes dominulus (hymenoptera: Vespidae) as a trace metal accumulator. Chemosphere 64:697-703

Uttah EC, Uttah C, Akpan PA, Ikpeme EM, Ogbeche J, Usip JO (2008) Bio-survey of plankton as indicators of aquatic quality for recreational activities in Calabar River, Nigeria. J Appl Sci Environ Manage 12:35-42
Zaghloul A, Saber M, Abd-El-Hady M (2019) Physical indicators for pollution detection in terrestrial and aquatic ecosystems. Bull NRC 43:120-126

Zancan S, Trevisan R, Paoletti M (2006) Soil algae composition under different agro-ecosystems in north-eastern Italy. Agric Ecosystems Environ 112:1-12

Zannatul F, Muktadir AKM (2009) A review: potentiality of zooplankton as biological indicators. Am J Appl Sci 6:1815-1819

\section{Publisher's Note}

Springer Nature remains neutral with regard to jurisdictional claims in published maps and institutional affiliations.

\section{Submit your manuscript to a SpringerOpen ${ }^{\circ}$ journal and benefit from:}

- Convenient online submission

- Rigorous peer review

- Open access: articles freely available online

- High visibility within the field

- Retaining the copyright to your article

Submit your next manuscript at $\boldsymbol{\nabla}$ springeropen.com 